\title{
Procalcitonin beyond the acute phase: novel biomediator properties?
}

\author{
Carolina Panico and Eric Nylen
}

\begin{abstract}
Since inflammation has been linked to carcinogenic events, discovery of relevant biomarkers may have important preventative implications. Procalcitonin (ProCT) has been shown to be an important prognostic biomarker in severe inflammatory conditions, but there is no data regarding its biomarker role, if any, beyond the acute phase. In a recent study published in BMC Medicine, Cotoi et al. analyzed whether serum ProCT levels in healthy individuals are associated with mortality outcomes. The results are affirmative in that baseline ProCT was shown to be strongly and independently associated with all-cause and cancer mortality and with the incidence of colon cancer in men. By contrast, the study indicated that high sensitivity C-reactive protein was independently associated with cardiovascular mortality but not with cancer mortality in men. Thus, baseline levels of ProCT appear to have prognostic biomarker implications potentially related to its emerging biomediator action(s).
\end{abstract}

Keywords: Biomarker, Carcinogenesis, Mortality, Procalcitonin

\section{Procalcitonin}

Procalcitonin (ProCT) is the prohormone of the peptide calcitonin normally produced by $\mathrm{C}$ cells of the thyroid gland and by certain neuroendocrine cells in the lung. However, in response to bacterial and/or severe systemic inflammatory exposure, cells throughout the body secrete ProCT and its associated peptides (Table 1) [1]. In addition to this biomarker role in septic-like conditions, ProCT also appears to act as a biomediator, whereby it has direct and independent toxic effects on cells $[2,3]$. Although there has been ample documentation that serum ProCT increases multifold in various septic-like conditions, where it correlates with severity and mortality $[1,4,5]$, there has been little attention drawn to the possible influence of baseline ProCT and its associated peptides that circulate at low concentrations in healthy individuals [6].

\section{The Malmo Diet and Cancer Cohort}

A recent study published in BMC Medicine by Cotoi et al. observed the effects of ProCT on all-cause and cancer mortality in healthy individuals [7]. The Malmo Diet and Cancer Cohort is a large longitudinal prospective

\footnotetext{
* Correspondence: enylen@gmail.com

Department Endocrinology, VAMC, and George Washington University School of Medicine, Washington, DC, USA
}

population study initiated to determine dietary habits and genetic markers that could predict the incidence of cancers in the general population, and to investigate cardiovascular risk factors and early atherosclerosis using three national registries with validated outcomes. Of the 28,449 individuals enrolled in the Malmo Diet and Cancer Cohort, 6,094 were part of the cardiovascular arm of the study. Individuals previously diagnosed with coronary disease or stroke and individuals with previous diagnoses of cancer were excluded from the study. Plasma measurements for ProCT were available for 3,322 participants. In a previous study by these investigators using the same cohort, there was a positive association between plasma levels of ProCT and the incidence of coronary events and deaths in healthy individuals [8]. However, following appropriate statistical adjustments, ProCT was not an independent predictor of cardiovascular risk. Although ProCT is a recognized biomarker, it's scope of utility has expanded in the recent past to include aspects beyond the acute phase itself. The current study by Cotoi et al. recognized that the baseline levels of ProCT might have prognostic features possibly different from those of other biomarkers, such as C-reactive protein [7].

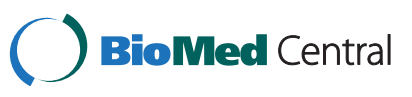

(c) 2013 Panico and Nylen; licensee BioMed Central Ltd. This is an Open Access article distributed under the terms of the Creative Commons Attribution License (http://creativecommons.org/licenses/by/2.0), which permits unrestricted use, distribution, and reproduction in any medium, provided the original work is properly cited. 
Table 1 The ratio of baseline procalcitonin and its associated peptides in the serum of healthy individuals [6]

\begin{tabular}{ll}
\hline Peptides & Ratio \\
\hline Calcitonin & 1 \\
Procalcitonin & 0.1 \\
Aminoprocalcitonin & 2.3 \\
Calcitonin carboxyl-terminus peptide-1 & 1.7 \\
\hline
\end{tabular}

\section{Procalcitonin and cancer mortality}

In the study by Cotoi et al., adjusted baseline ProCT was strongly associated with the risk of all-cause and cancer mortality and with incidence of colon cancer in men [7]. The cumulative incidence of all-cause mortality increased by quartile of baseline ProCT levels. By contrast, high sensitivity C-reactive protein was independently associated with cardiovascular mortality but not with cancer mortality in men. Neither biomarker correlated with incident mortality in women. A significant correlation was, however, found between ProCT quartiles and cystatin $\mathrm{C}$, confirming previous data showing that renal function influences plasma levels of ProCT [6]. Although these results are of considerable interest, one important caveat is the assay applied. The assay used for ProCT measurements in the study has its lower detection limit at $10 \mathrm{pg} / \mathrm{mL}$ (ProCa-S; BRAHMS GmbH, Hennigsdorf, Germany). This is considered a sensitive assay, but the levels of baseline ProCT obtained, especially in women, are at or below the functional performance of the assay, weakening the overall reliability. As shown in Table 1, ProCT consists of additional peptides other than the intact prohormone itself. For example, the baseline levels of the amino portion of ProCT, which is not detected by the authors' assay, exceed that of calcitonin and the other peptides, and may therefore yield more accurate information [6].

\section{Potential pathological pathways}

Although the underlying mechanisms linking ProCT with carcinogenesis are unclear, in the context of the study by Cotoi et al. [7], there are several pathological pathways that may have relevance with respect to ProCT (Figure 1).

\section{Procalcitonin and cytokines}

The specific stimuli for ProCT secretion are not well understood although proinflammatory cytokines such as tumor necrosis factor, and IL-1beta have been reported to stimulate ProCT secretion [1]. Moreover, it is known that ProCT induces upregulation of inflammatory cytokines in in vitro and in vivo studies [2,3,9]. Some of these cytokines are an important link between inflammation and carcinogenesis [10-15]. In particular, IL-6 seems to positively correlate to ProCT levels in various pathological conditions [1,2]. Elevated expression of IL-6 has been detected in various epithelial tumors [16]. Furthermore, several studies implicate IL-6 as a critical mediator of mammary stem cell renewal in both normal and tumor contexts [17].

\section{Procalcitonin and reactive oxygen species}

Various stimuli lead to generation of reactive oxygen species. For example, inducible nitric oxide synthase is associated with cytotoxicity via formation of iron-nitrosyl complexes and inactivation of iron-containing enzymes [18] and may play a role in tumor growth and metastasis $[19,20]$. Araujo et al. observed that inducible nitric oxide synthase is upregulated after the application of ProCT in mesangial cells [2], suggesting that increases in ProCT can be linked to an increase in reactive oxygen species, which in turn has been associated with cancers such as colon cancer [21].

\section{Procalcitonin and the Wnt pathway}

The Wnt pathway has emerged as a critical pathway in several aspects of carcinogenesis [22-24], including aberrant activation in colorectal cancer [25]. Interestingly, the Wnt pathway is significantly upregulated by the application of ProCT [2], suggesting another route for ProCT to carcinogenesis.

\section{Procalcitonin and DNA methylation}

Alterations in circulating DNA can be found in patients with various malignancies, and methylation patterns of serum DNA seem to correlate with clinical presentation

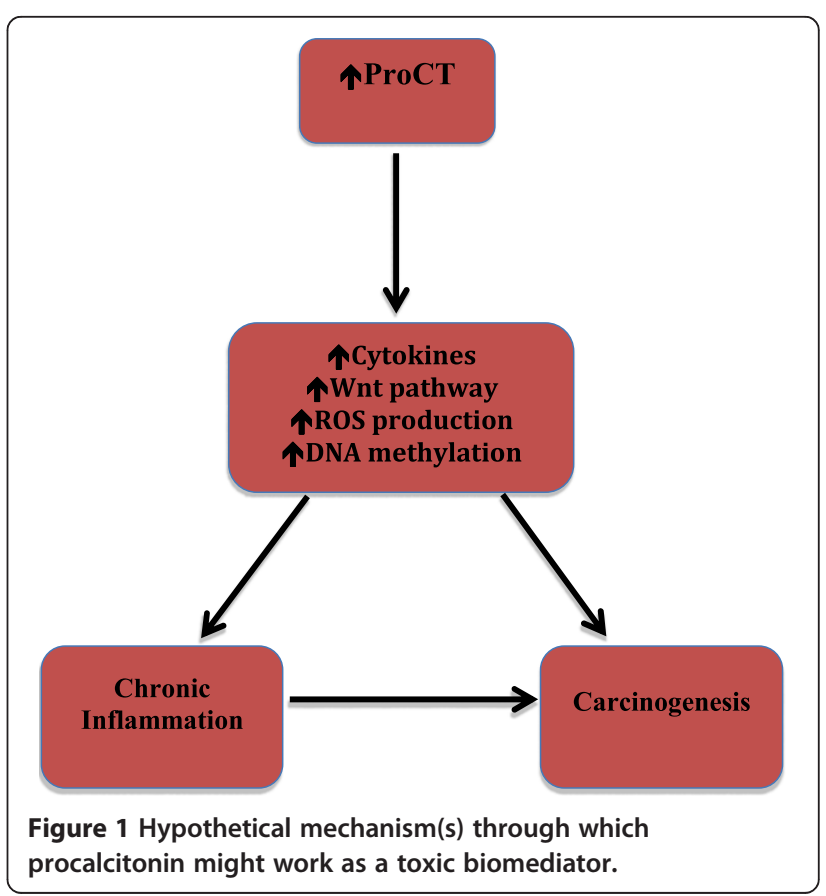


and outcome in patients with cancer [15,26]. Interestingly, ProCT correlates with DNA methylation not only in patients with cancer but also those with chronic kidney disease [27].

\section{Discussion}

The results of the study by Cotoi et al. highlight novel aspects of ProCT beyond the well-documented acute phase response [1,7]. The fact that ProCT presented a different association pattern from high sensitivity C-reactive protein suggests that ProCT is a biomarker of specific inflammatory processes. Moreover, in the present study, the authors show that after adjustment for cystatin $\mathrm{C}$ the association between ProCT and colon cancer in men remained statistically significant, suggesting a specific relationship between cancer and ProCT levels in spite of renal function. Further work is required to determine the potential pathways through which this effect may occur. The importance of the study by Cotoi et al. is to uncover a potentially relevant biomarker for early events in the carcinogenic process and thereby enhance preventative strategies. However, essentially nothing is currently known regarding baseline physiological and pathophysiological variability in ProCT or its associated peptides. Most likely, further optimization of the 'ProCT' assay would have to be achieved, as discussed above, to establish if the results of Cotoi et al. could be used clinically. Intriguingly, ProCT may have a role as a biomediator considering its actions relevant to carcinogenesis (Figure 1); future research may also focus on means to alter ProCT action [28].

\section{Conclusion}

Cotoi et al. found an independent link between higher baseline plasma ProCT levels in healthy men with subsequent mortality outcomes and colon cancer, suggesting that subtle but subclinically elevated ProCT might have prognostic implications. Although an epiphenomenon cannot be excluded or causality be proven, the link could be related to emerging biomediator properties of ProCT that merit further scrutiny.

\section{Abbreviations}

IL: Interleukin; ProCT: Procalcitonin.

\section{Competing interests}

The authors declare that they have no competing interests.

\section{Authors' contributions}

$\mathrm{CP}$ reviewed the literature and conceived and produced the illustrations. EN wrote and edited the commentary. Both authors read and approved the final manuscript.

Received: 15 August 2013 Accepted: 15 August 2013

Published: 28 August 2013

\section{References}

1. Becker $\mathrm{KL}$, Snider $\mathrm{R}$, Nylen ES: Procalcitonin in sepsis and systemic inflammation: a harmful biomarker and a therapeutic target. Brit $J$ Pharmacol 2010, 159:253-264.

2. Araujo M, Doi SQ, Palant CE, Nylen E, Becker KL: Procalcitonin induced cytotoxicity and apoptosis in mesangial cells: implications for septic renal injury. Inflamm Res 2013 [Epub ahead of print].

3. Liappis AP, Gibbs KW, Nylen ES, Yoon B, Snider RH, Gao B, Becker KL: Exogenous procalcitonin evokes a pro-inflammatory cytokine response. Inflamm Res 2011, 60:203-207.

4. Steinwald PM, Whang KT, Becker KL, Snider RH, Nylen ES, White JC: Elevated calcitonin precursor levels are related to mortality in an animal model of sepsis. Crit Care 1999, 3:11-16.

5. Whang KT, Steinwald PM, White JC, Nylen ES, Snider RH, Simon GL, Goldberg RL, Becker KL: Serum calcitonin precursors in sepsis and systemic inflammation. J Clin Endocr Metab 1998, 83:3296-3301.

6. Snider RH Jr, Nylen ES, Becker KL: Procalcitonin and its component peptides in systemic inflammation: immunochemical characterization. J Invest Med 1997, 45:552-560.

7. Cotoi OS, Manjer J, Hedblad B, Engström G, Melander O, Schiopu A: Plasma procalcitonin is associated with all-cause and cancer mortality in apparently healthy men: a prospective population-based study. BMC Med 2013, 11:180.

8. Schiopu A, Hedblad B, Engstrom G, Struck J, Morgenthaler NG, Melander O: Plasma procalcitonin and the risk of cardiovascular events and death: a prospective population-based study. J Intern Med 2012, 272:484-491.

9. Zannoni A, Giunti M, Bernardini C, Gentilini F, Zaniboni A, Bacci ML, Forni M: Procalcitonin gene expression after LPS stimulation in the porcine animal model. Res Vet Sci 2012, 93:921-927.

10. Balkwill F, Mantovani A: Inflammation and cancer: back to Virchow? Lancet 2001, 357:539-545.

11. Hussain SP, Harris CC: Inflammation and cancer: an ancient link with novel potentials. Int J Cancer 2007, 121:2373-2380.

12. Okada F: Beyond foreign-body-induced carcinogenesis: impact of reactive oxygen species derived from inflammatory cells in tumorigenic conversion and tumor progression. Int J Cancer 2007, 121:2364-2372.

13. Mantovani A, Allavena P, Sica A, Balkwill F: Cancer-related inflammation. Nature 2008, 454:436-444.

14. Coussens LM, Werb Z: Inflammation and cancer. Nature 2002, 420:860-867.

15. Shanmugam MK, Sethi G: Role of epigenetics in inflammation-associated diseases. Subcell Biochem 2012, 61:627-657.

16. Naka T, Nishimoto N, Kishimoto T: The paradigm of IL-6: from basic science to medicine. Arthritis Res 2002, 4:S233-S242.

17. Sansone P, Storci G, Tavolari S, Guarnieri T, Giovannini C, Taffurelli M, Ceccarelli C, Santini D, Paterini P, Marcu KB, Chieco P, Bonafè M: IL-6 triggers malignant features in mammospheres from human ductal breast carcinoma and normal mammary gland. J Clin Invest 2007, 117:3988-4002.

18. Beckman JS, Beckman TW, Chen J, Marshall PA, Freeman BA: Apparent hydroxyl radical production by peroxynitrite: implications for endothelial injury from nitric oxide and superoxide. Proc Natl Acad Sci 1990, 87:1620-1624

19. Celenk F, Bayramoglu I, Yilmaz A, Menevse A, Bayazit Y: Expression of cyclooxygenase-2, 12-lipoxygenase, and inducible nitric oxide synthase in head and neck squamous cell carcinoma. J Craniofac Surg 2013, 24:1114-1117.

20. Takaoka K, Hidaka S, Hashitani S, Segawa E, Yamamura M, Tanaka N, Zushi Y, Noguchi K, Kishimoto H, Urade M: Effect of a nitric oxide synthase inhibitor and a CXC chemokine receptor-4 antagonist on tumor growth and metastasis in a xenotransplanted mouse model of adenoid cystic carcinoma of the oral floor. Int J Oncol 2013, 43:737-745.

21. Ullman TA, Itzkowitz SH: Intestinal inflammation and cancer. Gastroenterology 2011, 140:1807-1816.

22. Bienz M, Clevers H: Linking colorectal cancer to Wnt signaling. Cell 2000, 103:311-320.

23. Polakis P: Wnt signaling and cancer. Gene Dev 2000, 14:1837-1851.

24. Morin PJ, Sparks AB, Korinek V, Barker N, Clevers H, Vogelstein B, Kinzler KW: Activation of beta-catenin-Tcf signaling in colon cancer by mutations in betacatenin or APC. Science 1997, 275:1787-1790.

25. Korinek V, Barker N, Morin PJ, van Wichen D, de Weger R, Kinzler KW, Vogelstein B, Clevers $\mathrm{H}$ : Constitutive transcriptional activation by a 
beta-catenin-Tcf complex in APC-/- colon carcinoma. Science 1997, 275:1784-1787.

26. Morrison WB: Inflammation and cancer: a comparative view. J Vet Intern Med 2012, 26:18-31.

27. Kato S, Lindholm B, Stenvinkel P, Ekstrom TJ, Luttropp K, Yuzawa Y, Yasuda $Y$, Tsuruta Y, Maruyama S: DNA hypermethylation and inflammatory markers in incident Japanese dialysis patients. Nephron 2012, 2:159-168.

28. Nylen ES, Whang KT, Snider RH Jr, Steinwald PM, White JC, Becker KL: Mortality is increased by procalcitonin and decreased by an antiserum reactive to procalcitonin in experimental sepsis. Crit Care Med 1998, 26:1001-1006.

doi:10.1186/1741-7015-11-189

Cite this article as: Panico and Nylen: Procalcitonin beyond the acute phase: novel biomediator properties?. BMC Medicine 2013 11:189.

\section{Submit your next manuscript to BioMed Central and take full advantage of:}

- Convenient online submission

- Thorough peer review

- No space constraints or color figure charges

- Immediate publication on acceptance

- Inclusion in PubMed, CAS, Scopus and Google Scholar

- Research which is freely available for redistribution 